Çukurova Üniversitesi Mühendislik Mimarlık Fakültesi Dergisi, 31(ÖS 1), ss. ÖS 155-ÖS 162, Ağustos 2016

Çukurova University Journal of the Faculty of Engineering and Architecture, 31(ÖS 1), pp. SI 155-SI 162, August 2016

\title{
Farklı Kaynak Ağız Açılarının 307Si Elektroduyla Kaynak Edilmiş Mıl-A 46100 Zırh Çeliğinin Mekanik Özelliklerine Etkisinin İncelenmesi
}

\author{
Suat KURT $^{* 1}$, Celal EVCİ², Halil IŞIK ${ }^{1}$, Mehmet Samir IŞIK ${ }^{1}$ \\ ${ }^{1}$ Kara Harp Okulu, Makine Mühendisliği Böl., Ankara, Türkiye \\ ${ }^{2}$ Kara Harp Okulu, Savunma Bilimleri Enst., Teknoloji Yönetimi A.D., Ankara, Türkiye
}

Geliş tarihi: 04.01.2016 Kabul tarihi: 04.04.2016

\section{Özet}

Bu çalışmada, yüksek sertlikli zırh çeliği östenik paslanmaz çelik elektrot kullanılarak MIG (Metal Inert Gas) yöntemiyle kaynak edilmiştir. MIL A 46100 zrh çeliğinden, 6 farklı açıda plakalar hazırlanmış ve 307Si östenitik paslanmaz çelik elektrot kullanılarak kaynak edilmiştir. Hazırlanan bu numunelere çekme deneyi ve 3 bölgeyi kapsayacak şekilde (kaynak metali, 1sı tesiri altında kalan bölge, esas metal bölgesi) mikro sertlik taraması yapılmıştır. Elde edilen sonuçlar karşılıklı olarak değerlendirilerek en uygun kaynak açısı belirlenmiştir.

Anahtar Kelimeler: Zırh çeliği, Östenitik kaynak teli, Metal ark kaynağı, Çekme testi, Mikrosertlik tarama

\section{Experimental and Numerical Analaysis of Weld Geometry and Groove Angle Effect on the Microstructure and Mechanical Properties of the Welded High Hardness Armor Plates}

\begin{abstract}
This study covers an investigation on welding high strength armor steels with austenitic filler material using Gas Metal Arc Welding process. Armor plates conforming to MIL A 46100 standard were prepared with six different groove angles using $307 \mathrm{Si}$ austenitic stainless steel electrode. Welded test specimens were subjected to tensile testing and microhardness measurements in three zones (fusion zone, heat affected zone and base metal zone) were recorded. Comparing the results obtained from both tensile testing and microhardness measurements, the optimum groove angle to result in the highest mechanical properties is determined.
\end{abstract}

Keywords: Armor steel, Austenitic welding wire, Metal arc welding, Tensile testing, Microhardness measurement

\footnotetext{
* Sorumlu yazar (Corresponding author): Suat KURT, Kara Harp Okulu, Makine Mühendisliği Bölümü, Ankara.suatkurt@kho.edu.tr,suatkurt81@gmail.com
} 
Farklı Kaynak Ağız Açılarının 307Si Elektroduyla Kaynak Edilmiş Mıl-A 46100 Zırh Çeliğinin Mekanik Özelliklerine Etkisinin İncelenmesi

\section{GíRiş}

Zırh çelikleri, her ne kadar malzeme teknolojisi gelişse de kolay ulaşılabilirlik ve uygun maliyet nedeniyle yaygın olarak kullanılmaktadır. Zırh çeliklerinin en çok kullanıldığı alan askeri araçlar tanklar, zırhlı personel taşıyıcılar, obüsler olmaktadır. Bu tür araçların maruz kalacakları tüm tehditlere karşı maksimum dayanımı göstermeleri gerekmektedir. Ayrica silah teknolojisinin de her geçen gün gelişmesi zırhların da gelişimini kaçınılmaz kılmaktadır [1,2,3].

$\mathrm{Bu}$ araçların imalatında farklı tasarımlar için plakların birleştirilmesine, bunu için ise kaynak işlemine gereksinim duyulmaktadır. Ancak kaynak işlemi esnasında gerçekleşen 1S1 girdisi malzemenin mekanik davranışını etkileyen parametreler arasında yer almaktadır $[2,4]$.

Is1 girdisi özellikle 1S1 tesiri altındaki bölge (ITAB)'ın büyüklüğünü ve buradaki tane yapılarını etkilemektedir. Ortaya çıkan yap1 ise kaynaklı birleştirmenin mukavemetini belirlemektedir. $\mathrm{Bu}$ etki, kaynağın türü, kullanılan elektrot özellikleri, kullanılan ana malzeme, voltaj gibi parametrelere bağlıdır [5].

Bu çalışmada MIL-A-46100 zırh çeliği plakaları, gazaltı metal ark kaynak yöntemi ile $1 \mathrm{~mm}$ çaplı 307Si östenitik paslanmaz çelik elektrot kullanılarak birleştirilmiş ve mekanik özellikleri incelenmiştir.

\section{DENEYSEL CALIŞMALAR}

\subsection{Kullanılan Malzemeler}

Bu çalışmada; kaynak işlemi sonrası mekanik özelliklerini incelemek istediğimiz MIL A 46100 zırh çeliği esas metal (iş parçası) olarak, 307Si malzemesi ise kaynak elektrotu olarak kullanılmıştır. MIL A 46100 zırh çeliğinin kimyasal bileşimi Çizelge 1'de, 307Si elektrotunun kimyasal bileşimi ise Çizelge 2'de verilmiştir.
Çizelge 1. MIL A 46100 zırh çeliğinin kimyasal bileșimi [6]

\begin{tabular}{|c|c|c|c|c|c|}
\hline $\begin{array}{c}\text { MIL A } \\
46100\end{array}$ & $\mathrm{C}$ & $\mathrm{Cr}$ & $\mathrm{Ni}$ & $\mathrm{Mo}$ & $\mathrm{Mn}$ \\
\hline $\begin{array}{c}\text { Kimyasal } \\
\text { Bileşim } \\
(\%)\end{array}$ & \begin{tabular}{c}
0,3 \\
\hline
\end{tabular} & 1,6 & $\begin{array}{c}\text { Maksimum } \\
1,85\end{array}$ & 0,5 & 0,95 \\
\hline
\end{tabular}

Çizelge 2. Kaynak telinin mekanik özellikleri ve kimyasal bileşimi [6]

\begin{tabular}{|c|c|c|c|c|c|c|c|}
\hline $307 \mathrm{Si}$ & $\mathrm{C}$ & $\mathrm{Si}$ & $\mathrm{Mn}$ & $\mathrm{P}$ & $\mathrm{S}$ & $\mathrm{Cr}$ & $\mathrm{Ni}$ \\
\hline $\begin{array}{c}\text { Kimyasal } \\
\text { Bileşim } \\
(\%)\end{array}$ & 0,08 & 0,8 & 7 & 0,017 & 0,012 & 19 & 9 \\
\hline
\end{tabular}

Kaynak işleminde kullanılan elektrotun mikro yapısını bilmek, esas metalle uyum sağlayıp sağlamayacağı açısından önemlidir. Bunun tespiti için Şekil 1'deki Schaeffler diyagramından [7] yararlanılabilir. Krom $(\mathrm{Cr})$ ve Nikel (Ni) eş değerliklerine bakıldığında; (1) numaralı denklem yardımiyla $\mathrm{Cr}_{\mathrm{ess}}=20,7$, (2) numaralı denklem yardımıyla $\mathrm{Ni}_{\mathrm{es}}=14,4$ olarak hesaplanır.

$N i_{e S ̧}=\% N i+30 x \% C+0,5 x \% M n$

$C r_{e s}=\% \mathrm{Cr}+30 \mathrm{Mo}+1,5 x \% \mathrm{Si}$

Hesaplanan Krom ve Nikel eşdeğerlikleri Schaeffler diyagramı üzerine yerleştirildiğinde; 307Si elektrotunun, \%1 ferritten teşkil östenitik bir yapıya sahip olduğu sonucuna varılır. Kaynakta kullandığımız esas metal ise düşük alaşımlı martenzitik MIL-A 46100 zırh çeliğidir. Bu kaynak işleminde elektrotun östenitik olması, ön 1sıtma gerekliliğini ortadan kaldırmıştır. Yani, oda sıcaklığında kaynak edilebilme imkânı oluşmuştur. Aynı zamanda elektrot, içerdiği Mangan (Mn) sayesinde $850^{\circ} \mathrm{C}$ 'ye kadar olan sicakliklarda dayanımını koruyabilir. Buna bağlı olarak kaynak edilebilirlik artar, işçilik azalır ve zamandan tasarruf edilmiş olur [8]. 


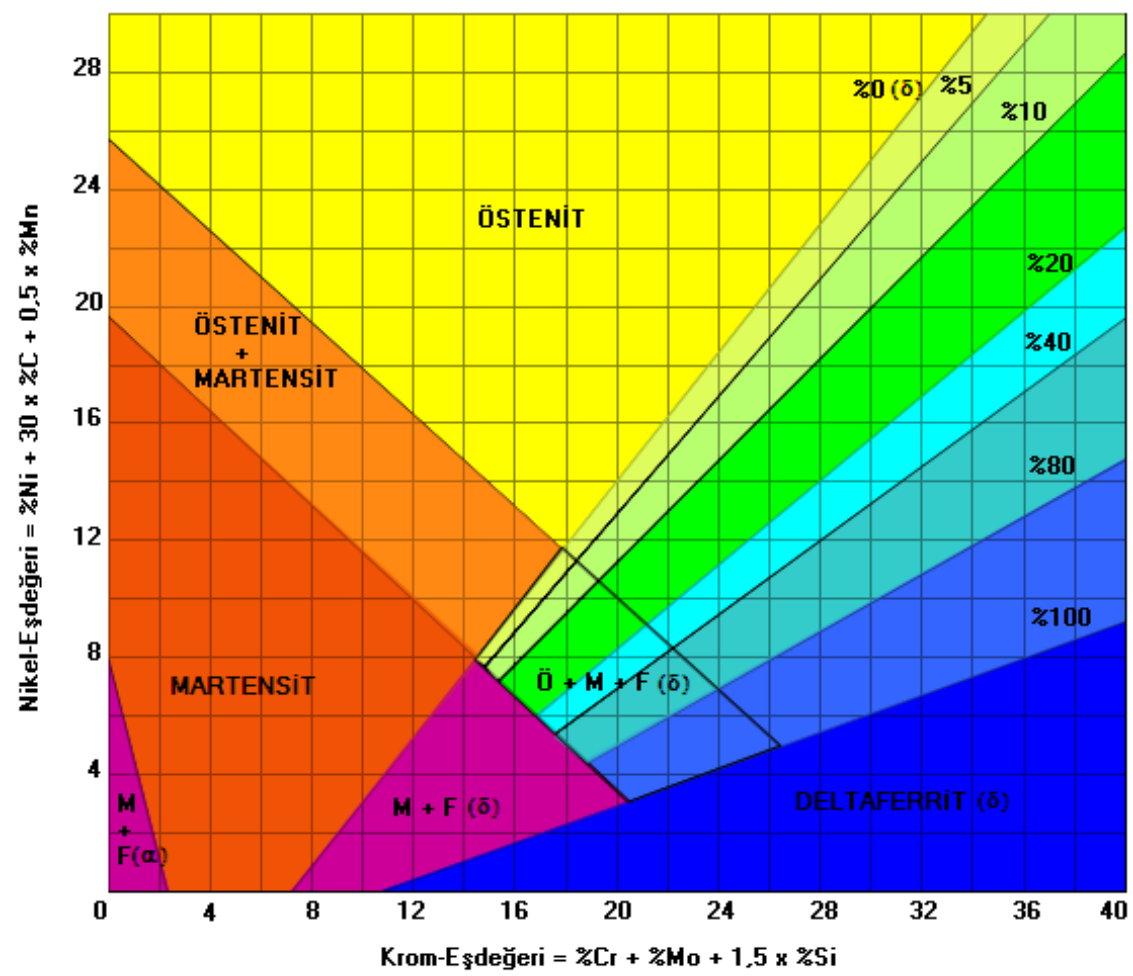

Şekil 1. 307Si kaynak metaline ait fazları gösteren Schaeffler diyagramı

Kaynak ișlemleri öncesi MIL A 46100 malzemesinden hazırlanan plakalar, çarpılma olmaması ve kaynak dikişinin daha sağlıklı olması amacıyla Şekil 2'deki gibi sabitlenerek kaynağa hazır hale getirilmiştir.

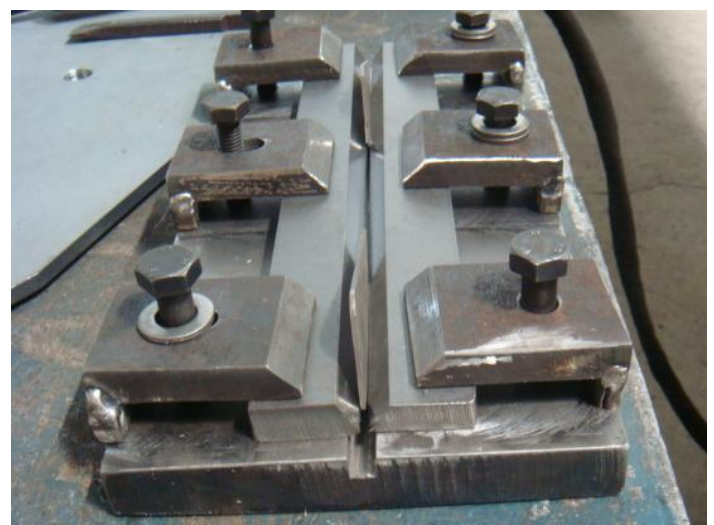

Şekil 2. Kaynak işlemi öncesi sabitlenmiş MIL A 46100 plakaları
Kaynağa hazır hale getirilen MIL A 46100 zırh çeliği plakaları; $1 \mathrm{~mm}$ çapında $307 \mathrm{Si}$ elektrot kullanılarak, \%97 Argon $+\% 3 \quad \mathrm{CO}_{2}$ karışımlı koruyucu gaz altında, $\mathrm{V}$ kaynak ağız geometrisinde, 6 farklı açıda $\left(30^{\circ}, 36^{\circ}, 42^{\circ}, 48^{\circ}\right.$, $\left.54^{\circ}, 60^{\circ}\right), 3$ pasolu olarak birleştirilmiş̧ir. Birleştirme işlemlerindeki kaynak akımı 150A, kaynak gerilimi $24,5 \mathrm{~V}$, kaynak hızı ise $16 \mathrm{~cm} /$ dak olarak seçilmiştir. Elde edilen kaynaklı plakalardan, TS 287 EN 895 standardına uygun çekme numuneleri ve mikro-sertlik taramasında kullanılmak üzere $90 \times 15 \times 12 \mathrm{~mm}$ boyutlarında numuneler hazırlanmıştır. Çekme deneyi numunelerinin baş kısımlarına, çekme cihazının çenelerine daha iyi tutunmaları için dişler açılmıştır. Son olarak tüm numunelerin üzerindeki pürüzler ve kalıntılar taşlanarak, deneylere hazır hale getirilmiştir. Çekme deneyi için hazırlanan numuneler Şekil 3'te, mikro sertlik taraması için hazırlanan numune örneği ise Şekil 4'te gösterilmiştir. 
Farklı Kaynak Ă̆ız Açılarının 307Si Elektroduyla Kaynak Edilmiş Mıl-A 46100 Zırh Çeliğinin Mekanik Özelliklerine Etkisinin Incelenmesi

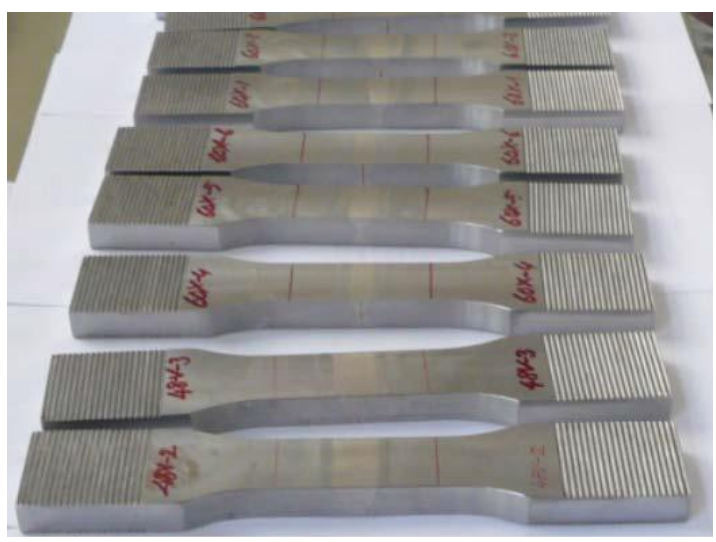

Şekil 3. Çekme deneyi için hazırlanmış numuneler

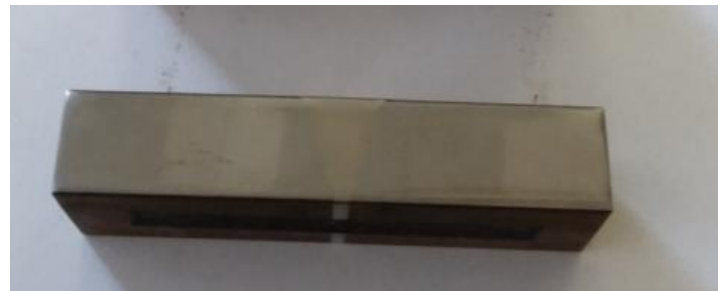

Şekil 4. Mikro sertlik taraması için hazırlanmış numune

\section{2. Çekme Deneyi}

TS 287 EN 895 standardına uygun olarak, farklı açılarda hazırlanan numunelerin deneyleri; $500 \mathrm{kN}$ kapasiteli çekme cihazıyla, $5 \mathrm{~mm} / \mathrm{dak}$ hızda gerçekleştirilmiştir. Her bir açı değeri için 5 farklı deney gerçekleştirilerek, çekme mukavemeti ve \% uzama değerleri elde edilmiş ve değerlerin ortalamaları hesaplanmıştır.

\subsection{Mikro Sertlik Taraması}

Deney numuneleri kaynak işleminden sonra zımparalanıp, parlatılarak yüzey pürüzlülükleri giderilmiş ve sertlik taramasına hazır hale getirilmiştir. Mikro sertlik taraması; QNESS marka, Q10 Plus model mikro sertlik deney cihazında, Vickers metoduyla, 0,5 kg'llk yük uygulayarak gerçekleştirilmiştir. Sertlik taraması, her bir numune için Şekil 5'te gösterildiği gibi;kaynak merkez çizgisinden yatayda $0,5 \mathrm{~mm}$ aralıklarla 24 noktada ve düşeyde $2 \mathrm{~mm}$ aralıklarla 5 sıra olacak şekilde toplam 120 noktada gerçekleştirilmiştir.

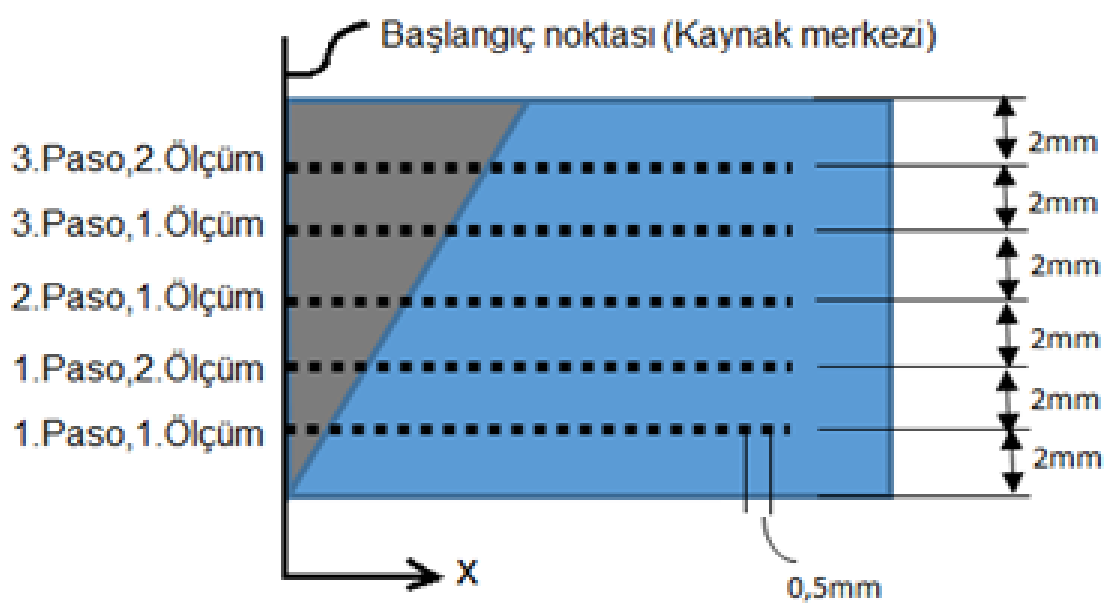

Şekil 5. Mikro sertlik taraması yapılan noktaların şematik görüntüsü

\section{SONUÇLAR VE TARTIŞMA}

\section{1. Çekme Deneyi Sonuçları}

Çekme deneyleri sonucunda gerçekleşen kopmalar, tüm numunelerde kaynak metali bölgesinden gerçekleşmiştir (Şekil 6). Deneyler sonucunda elde edilen ve hesaplanan veriler Çizelge 3'te sunulmuştur. Çizelge 3'teki değerlere göre; en yüksek dayanım 773,8 $\mathrm{MPa}$ değeri ile $48^{\circ}$ açılı numunede tespit edilmiştir. Bunu sırasıyla $42^{\circ}, 36^{\circ}, 60^{\circ}, 54^{\circ}, 30^{\circ}$ açıları takip etmektedir. 
Suat KURT, Celal EVCİ, Halil IŞIK, Mehmet Samir IŞIK.

Çizelge 3. Çekme mukavemeti

\begin{tabular}{|c|c|c|c|}
\hline & $\begin{array}{l}\text { Numune } \\
\text { Numarası }\end{array}$ & $\begin{array}{c}\text { Çekme } \\
\text { Mukavemeti } \\
\text { (MPa) }\end{array}$ & Ortalama \\
\hline \multirow{5}{*}{$30 \mathrm{~V}$} & 1 & 632 & \multirow{5}{*}{670,2} \\
\hline & 2 & 665 & \\
\hline & 3 & 715 & \\
\hline & 4 & 687 & \\
\hline & 5 & 652 & \\
\hline \multirow{5}{*}{$36 \mathrm{~V}$} & 1 & 830 & \multirow{5}{*}{740,0} \\
\hline & 2 & 755 & \\
\hline & 3 & 765 & \\
\hline & 4 & 720 & \\
\hline & 5 & 630 & \\
\hline \multirow{5}{*}{$42 \mathrm{~V}$} & 1 & 745 & \multirow{5}{*}{758,0} \\
\hline & 2 & 805 & \\
\hline & 3 & 750 & \\
\hline & 4 & 780 & \\
\hline & 5 & 710 & \\
\hline \multirow{5}{*}{$48 \mathrm{~V}$} & 1 & 774 & \multirow{5}{*}{773,8} \\
\hline & 2 & 730 & \\
\hline & 3 & 805 & \\
\hline & 4 & 790 & \\
\hline & 5 & 770 & \\
\hline \multirow{5}{*}{$54 \mathrm{~V}$} & 1 & 730 & \multirow{5}{*}{726,0} \\
\hline & 2 & 685 & \\
\hline & 3 & 715 & \\
\hline & 4 & 745 & \\
\hline & 5 & 755 & \\
\hline \multirow{5}{*}{$60 \mathrm{~V}$} & 1 & 718 & \multirow{5}{*}{735,8} \\
\hline & 2 & 759 & \\
\hline & 3 & 710 & \\
\hline & 4 & 762 & \\
\hline & 5 & 730 & \\
\hline
\end{tabular}

Çizelge 4. \% uzama değerleri

\begin{tabular}{|c|c|c|c|}
\hline & Ortalama & \%Uzama & Ortalama \\
\hline \multirow{5}{*}{$30 \mathrm{~V}$} & \multirow{5}{*}{670,2} & 5,2 & \multirow{5}{*}{5,7} \\
\hline & & 5,6 & \\
\hline & & 6,2 & \\
\hline & & 6,0 & \\
\hline & & 5,3 & \\
\hline \multirow{5}{*}{$36 \mathrm{~V}$} & \multirow{5}{*}{740,0} & 7,5 & \multirow{5}{*}{7,2} \\
\hline & & 7,7 & \\
\hline & & 7,8 & \\
\hline & & 6,8 & \\
\hline & & 6,4 & \\
\hline \multirow{5}{*}{$42 \mathrm{~V}$} & \multirow{5}{*}{758,0} & 6,5 & \multirow{5}{*}{7,0} \\
\hline & & 8,0 & \\
\hline & & 7,5 & \\
\hline & & 6,8 & \\
\hline & & 6,2 & \\
\hline \multirow{5}{*}{$48 \mathrm{~V}$} & \multirow{5}{*}{773,8} & 7,6 & \multirow{5}{*}{7,6} \\
\hline & & 9,0 & \\
\hline & & 6,4 & \\
\hline & & 7,2 & \\
\hline & & 7,9 & \\
\hline \multirow{5}{*}{$54 \mathrm{~V}$} & \multirow{5}{*}{726,0} & 8,3 & \multirow{5}{*}{8,7} \\
\hline & & 8,4 & \\
\hline & & 8,4 & \\
\hline & & 8,7 & \\
\hline & & 9,7 & \\
\hline \multirow{5}{*}{$60 \mathrm{~V}$} & \multirow{5}{*}{735,8} & 8,0 & \multirow{5}{*}{8,4} \\
\hline & & 7,8 & \\
\hline & & 9,4 & \\
\hline & & 8,0 & \\
\hline & & 8,6 & \\
\hline
\end{tabular}




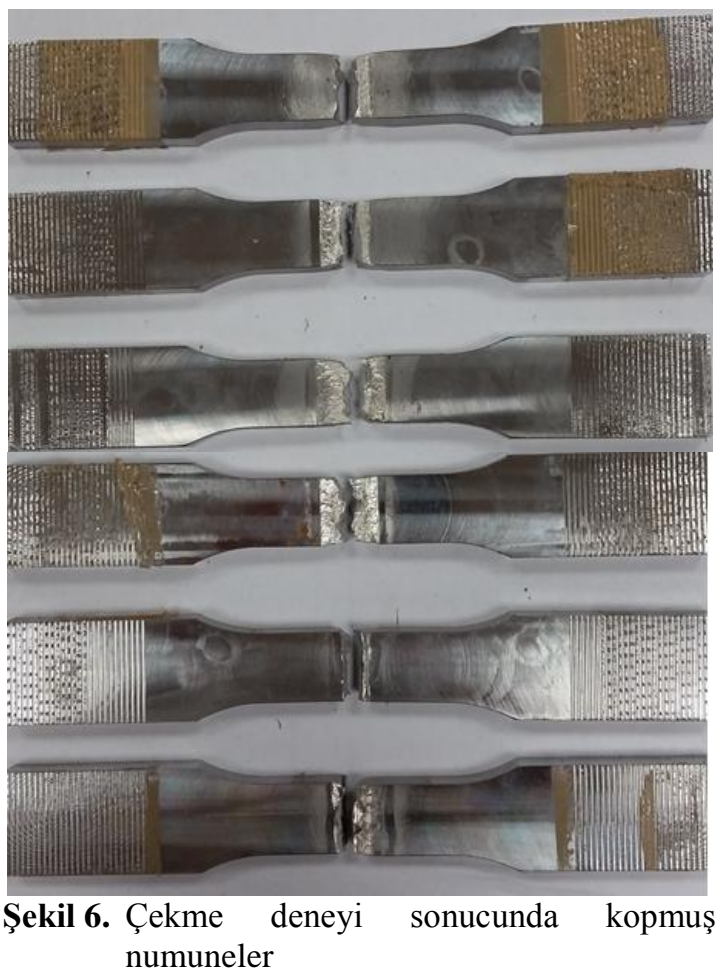

\subsection{Mikro Sertlik Dağılımları}

Bilindiği gibi, kaynak işlemleri sonrası Isı Tesiri Altında Kalan Bölgede (ITAB), mikro yapı değişimleri söz konusu olur. $\mathrm{Bu}$ bölgeler incelendiğinde (Şekil 7); kaynak metalinden uzaklaştıkça sırasıyla, iri taneli bölge, ince taneli bölge, kısmi dönüşmüş bölge ve son olarak 1sıdan etkilenmeyen esas metal bölgeleri gelmektedir.

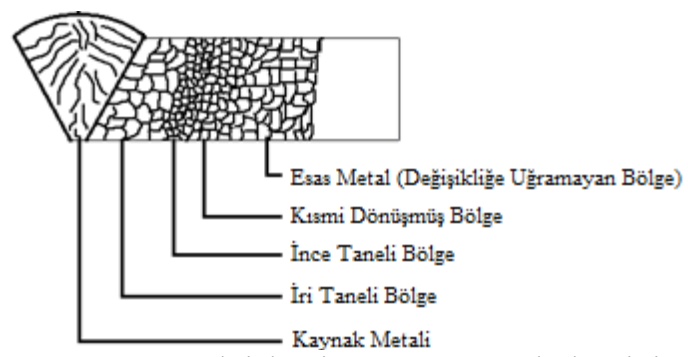

Şekil 7. Kaynak işlemi sonrası ITAB bölgesinin dağılımı

Tüm numunelerin, Şekil 5 'te verilen dağılıma göre elde edilen sertlik değerlerinin grafikleri Şekil 8'de sunulmuștur. Şekil 8 incelendiğinde; kaynak metalinin daha az sertliğe sahip olduğu, ince taneli bölgeye geçildiğinde sertliklerin en yüksek seviyede olduğu ve iri taneli bölgede beklendiği gibi düşüşlerin olduğu, son olarak esas metale yaklaştıkça değerlerin tekrar arttığı görülmektedir.

Çalışmamızda kullanılan elektrotun sertlik değerinin, esas metale göre çok düşük olması; tüm açılarda en düşük sertliğin kaynak metalinde çıkmasına sebep olmuştur. $\mathrm{Bu}$ kapsamda; incelemelerimiz kaynak metali bölgesinde yoğunlaşmıştır. Farklı açılara göre bu bölgelerin sertlik dağılımları Şekil 9'da verilmiştir.

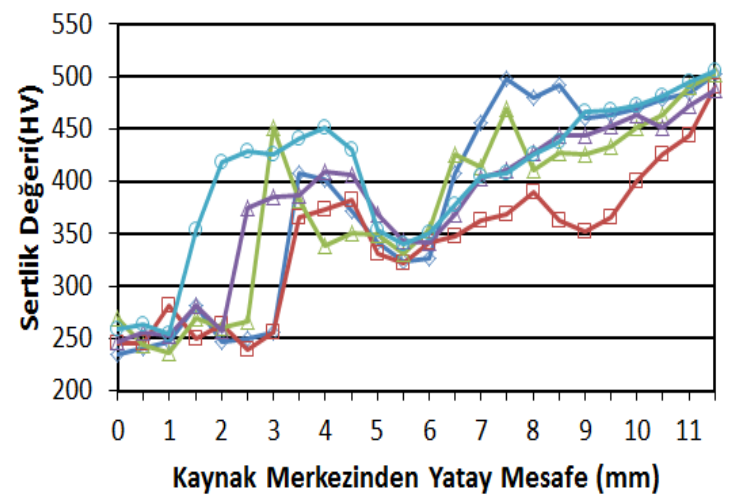

$\multimap$ 3.Paso,2.Ölçüm $\leftarrow$ 3.Paso,1.Ölçüm $\longleftarrow$ 2.Paso,1.Ölçüm $\leftarrow$ 1.Paso,2.Ölçüm $\subsetneq$ 1.Paso,1.Ölçüm

a) $30^{\circ}$

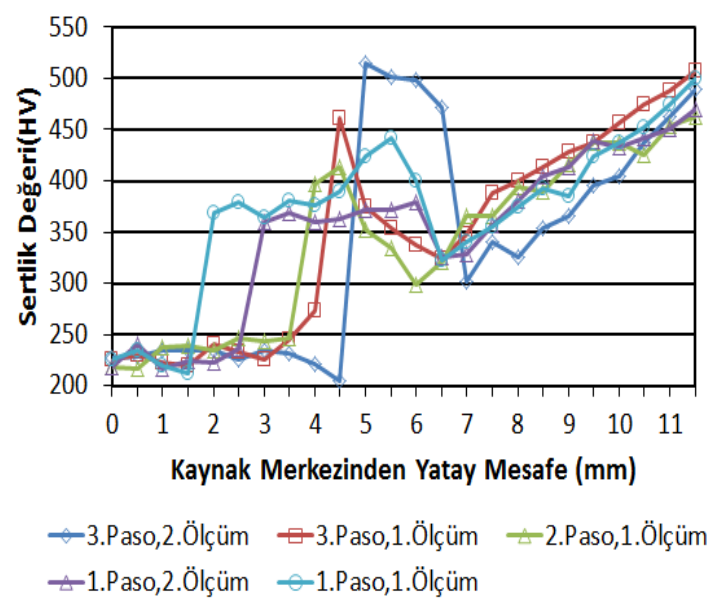

b) $36^{\circ}$ 


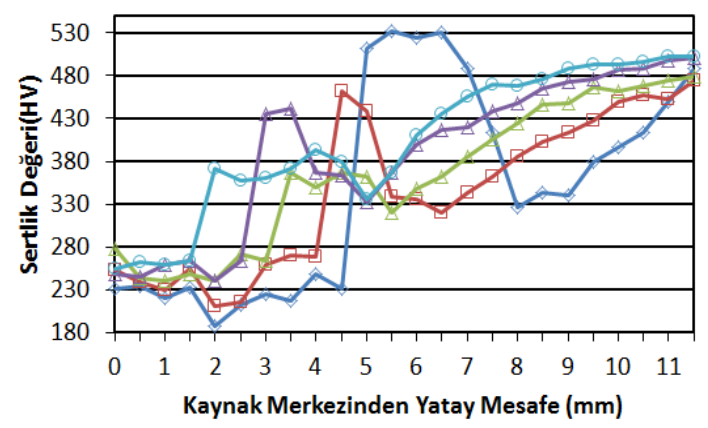

$\multimap$ 3.Paso,2.Ölçüm $\square$ 3.Paso,1.Ölçüm $\longleftarrow 2$.Paso,1.Ölçüm $\smile$ 1.Paso,2.Ölçüm $\rightleftharpoons 1$.Paso,1.Ölçüm

c) $42^{\circ}$

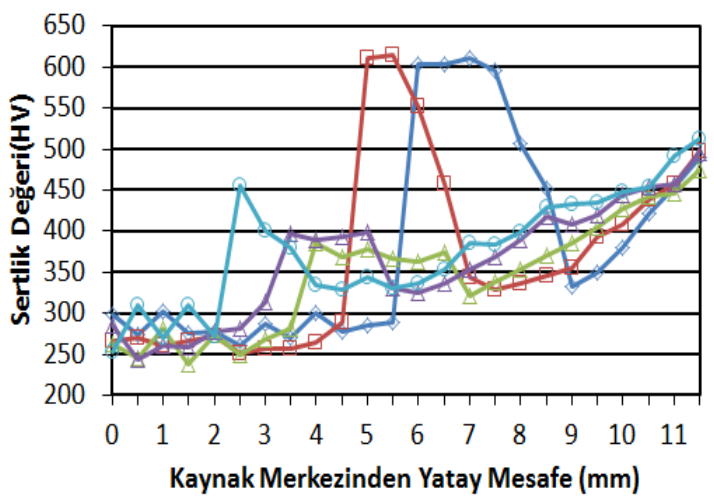

$\multimap$ 3.Paso,2.Ölçüm ־3.Paso,1.Ölçüm $\longleftarrow$ 2.Paso,1.ölçüm $\leftarrow$ 1.Paso,2.0̈lçüm $\subsetneq$ 1.Paso,1.Ölçüm

d) $42^{\circ}$

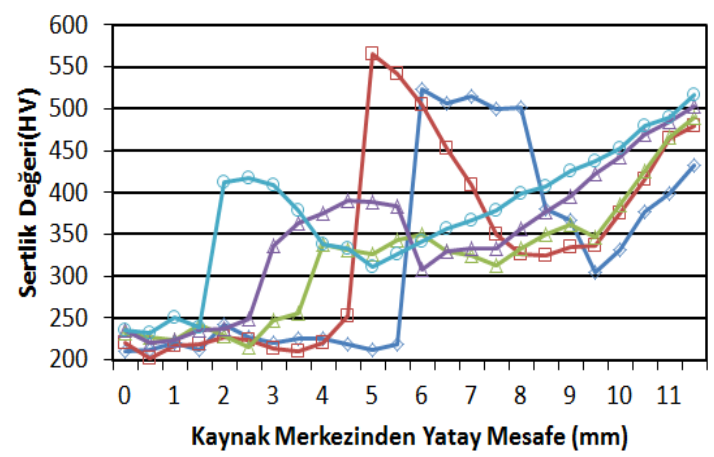

$\multimap$ 3.Paso,2.Ölçüm $\sqsubset$-3.Paso,1.Ölçüm $\leftarrow$-Paso,1.Ölçüm $\leftarrow$ 1.Paso,2.Ölçüm $\multimap$ 1.Paso,1.Ölçüm

d) $54^{\circ}$

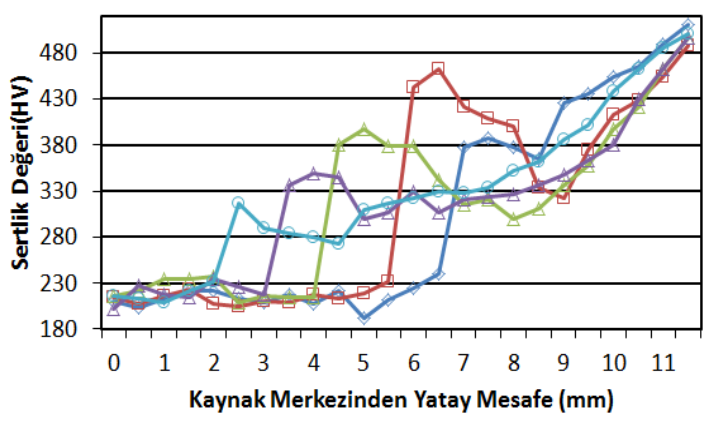

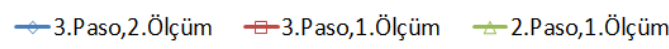
$\leftarrow$ 1.Paso,2.Ölçüm ־1.Paso,1.Ölçüm

e) $60^{\circ}$

Şekil 8. Farklı açılardaki numunelerin mikro sertlik dağılımları

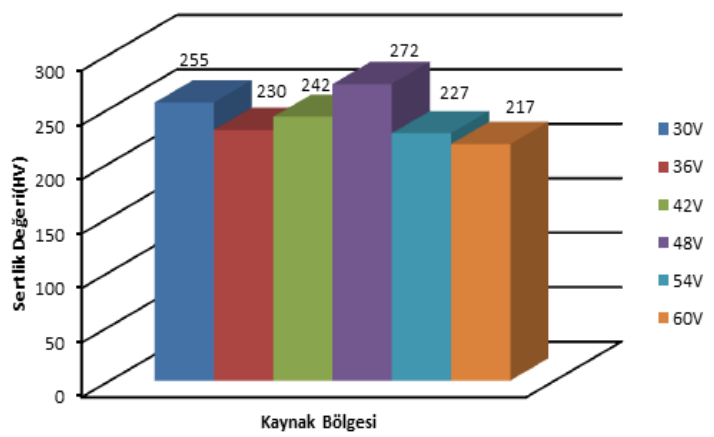

Şekil 9. Farklı açılara göre kaynak bölgelerinin sertlik değerleri

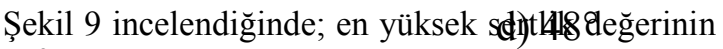
$48^{\circ}$ açıya sahip numunede çıktığ 1 görülmektedir. Bunu sırasıyla; $30^{\circ}, 42^{\circ}, 36^{\circ}, 54^{\circ}, 60^{\circ}$ açıları takip etmektedir.

\section{SONUÇLAR}

Çalışmamızda, MIL A 46100 zırh çeliği plakaları; $1 \mathrm{~mm}$ çapında $307 \mathrm{Si}$ elektrot kullanılarak, koruyucu gaz altında, $\mathrm{V}$ kaynak ağız geometrisinde, 6 farklı açıda $\left(30^{\circ}, 36^{\circ}, 42^{\circ}, 48^{\circ}\right.$, $\left.54^{\circ}, 60^{\circ}\right) 3$ pasolu olarak birleştirilmiştir. Numunelere çekme deneyi ve mikro sertlik taraması yapılmıştır. Varılan sonuçlar aşağıda sunulmuş̧ur: 
1. Çekme deneyi sonuçlarına göre, en yüksek dayanım $773,8 \mathrm{MPa}$ değeri ile $48^{\circ}$ açılı numunede tespit edilmiştir.

2. Çekme deneyi sonucunda; tüm numunelerde meydana gelen kopmalar, kaynak metali bölgesinden gerçekleşmiştir.

3. Tüm numunelerde, en düşük sertlik değerleri kaynak metali bölgesinde ortaya çıkmıştır.

4. Farklı açılara göre kaynak metali bölgelerinin sertlik değerleri karşılaştırıldığında; en yüksek sertlik değeri $48^{\circ}$ açılı numunede tespit edilmiştir.

5. Deney sonuçlarına göre; en yüksek sertlik ve çekme dayanımı $48^{\circ}$ açılı numunede ortaya çıktığından; MIL A 46100 çeliğinin 307Si elektrotu ile birleştirilmesinde $48^{\circ}$ optimum sonuçları vermiştir.

\section{KAYNAKLAR}

1. Atapek, H.Ş., 2011. Bor Katkılı Bir Zırh Çeliğinin Fiziksel Metalurjik Esaslar Doğrultusunda Geliştirilmesi ve Balistik Performansının Değerlendirilmesi” Kocaeli Üniversitesi.

2. Evci, C., 2009. Seramik Kompozit Zirh Sistemlerinin Darbe ve Balistik Özelliklerinin Belirlenmesi, Gazi Üniversitesi.

3. Kara, S., ve Korkut, M.H., 2012. "Zirh Çeliklerinde Kaynak Ağzı Tasarımının Metalurjik ve Mekanik Özelliklere Etkisinin Araştırılması", Makine Teknolojileri Elektronik Dergisi, Cilt: 9, No: 1,35-45.

4. Edwards, M.R. and Mathewson, A., 1997. The ballistic properties of tool steel as a potential improvise darmorplate, International Journal of Impact Engineering, 19/4 297-309.

5. Eryürek, B, İ., 2007. Kaynak Teknolojisi, Gazaltı Ark Kaynağı”, 2, 47-120, Askaynak Yayını, İstanbul.

6. www.askaynak.com.tr[web

7. http://www.oerlikon.com.tr/paslanmaz_celikler _mig_mag.html
8. Kara, S., ve Korkut, M.H., 2012. Zırhlı Muharebe Araçlarında Kullanılan Zırh Plakalarında Kaynak Sonrası Isıl İşlemin Birleşim Mukavemetine Etkisinin Araştırılması, Savunma Bilimleri Dergisi, Cilt/ 11, Say1/ 2, 159-171. 